This is an Accepted Manuscript of an article published by Taylor \& Francis in International Journal of Transgenderism on 26 Apr 2018, available online: https://www.tandfonline.com/doi/full/10.1080/15532739.2018.1456390.

\title{
A critical commentary on follow-up studies and "desistance" theories about transgender and gender non-conforming children.
}

Julie Temple-Newhook, Jake Pyne, Kelley Winters, Stephen Feder, Cindy Holmes, Jemma Tosh, Mari-Lynne Sinnott, Ally Jamieson \& Sarah Pickett

\begin{abstract}
Background: It has been widely suggested that over $80 \%$ of transgender children will come to identify as cisgender (i.e. desist) as they mature, with the assumption that for this $80 \%$, the trans identity was a temporary "phase." This statistic is used as the scientific rationale for discouraging social transition for pre-pubertal children. This article is a critical commentary on the limitations of this research and a caution against using these studies to develop care recommendations for gender non-conforming children.
\end{abstract}

Methods: A critical review methodology is employed to systematically interpret four frequentlycited studies that sought to document identity outcomes for gender non-conforming children (often referred to as "desistance" research).

Results: Methodological, theoretical, ethical, and interpretive concerns regarding four "desistance" studies are presented. The authors clarify the historical and clinical contexts within which these studies were conducted to deconstruct assumptions in interpretations of the results. The discussion makes distinctions between the specific evidence provided by these studies versus the assumptions that have shaped recommendations for care. The affirmative model is presented as a way to move away from the question of, "How should children's gender identities develop over time?" toward a more useful question: "How should children best be supported as their gender identity develops?"

Conclusion: The tethering of childhood gender diversity to the framework of "desistance" or "persistence" has stifled advancements in our understanding of children's gender in all its complexity. These follow-up studies fall short in helping us understand what children need. As work begins on the $8^{\text {th }}$ version of the Standards of Care by the World Professional Association for Transgender Health, we call for a more inclusive conceptual framework that takes children's voices seriously. Listening to children's experiences will enable a more comprehensive understanding of the needs of gender non-conforming children and provide guidance to scientific and lay communities.

Keywords: desistance; trans; transgender; gender dysphoria; children; youth; adolescents; follow-up; longitudinal; research

Funding: No funding was provided for the writing of this paper.

Ethical Approval: This article does not contain any studies with human participants performed by any of the authors. 


\section{Introduction}

In the media, among the lay public, and in medical and scientific journals, it has been widely suggested that over $80 \%$ of transgender ${ }^{1}$ children will come to identify as cisgender ${ }^{2}$ once they reach adolescence or early adulthood. This statement largely draws on estimates from four follow-up studies conducted with samples of gender non-conforming children in one of two clinics in Canada or the Netherlands (Drummond, Bradley, Peterson-Badali, \& Zucker, 2008; Steensma, Biemond, de Boer \& Cohen-Kettenis, 2011; Steensma, McGuire, Kreukels, Beekman \& Cohen-Kettenis, 2013; Wallien \& Cohen-Kettenis, 2008). This paper outlines methodological, theoretical, ethical, and interpretive concerns regarding these studies. We clarify the cultural, historical, and clinical contexts within which these studies were conducted to understand and to deconstruct the embedded foundational assumptions of the research as well as the widespread interpretations of the results. Some of these critiques have been offered elsewhere in commentaries, books and on-line forums (see Ehrensaft, 2016; Olson \& Durwood, 2016; Pyne, 2012; 2014; Serano, 2016; Winters, 2014); this analysis seeks to further this discussion by systematically engaging scholarly literature. This team of co-authors encompasses a range of theoretical and disciplinary perspectives which include: clinical care providers in pediatrics, family medicine, and psychology; researchers in the fields of sociology, psychology, neurobiology, and social work; and lived experience as trans and gender diverse people as well as parents and partners of trans and gender diverse people. Our theoretical approach echoes that of the World Professional Association for Transgender Health (2011), that transgender identity is "a matter of diversity, not pathology" (p. 4).

We recognize that numerous follow-up studies of gender non-conforming children have been reported since the mid-20 $0^{\text {th }}$ century (e.g. Green, 1987; Money \& Russo, 1979; Zucker \& Bradley, 1995; Zuger, 1984). In that era, most research in the domain focused on feminine expression among children assigned male at birth, with the implicit or explicit objective of preventing homosexuality or transsexuality. However, we focus here on the four most recent follow-up studies, published since 2008, which are most often cited as evidence for desistance theories.

\section{Concerns and Contributions: What Can and Cannot be Learned from Follow-Up Studies with Gender Non-Conforming Children}

Between 2008 and 2013, four follow-up studies of gender non-conforming children were published in peer-reviewed journals, with samples of children referred to one of two gender clinics in Toronto, Canada or in the Netherlands (Drummond et al., 2008; Steensma et al., 2011, 2013; Wallien \& Cohen-Kettenis, 2008). An oft-accepted interpretation of these findings is that approximately $80 \%$ of gender nonconforming children in these studies, by adolescence, identified with their sex assigned at birth. They are often said to have "desisted" from a prior

\footnotetext{
${ }^{1}$ We use the term trans or transgender when an individual's gender differs from the one assigned to them at birth and/or differs from what others expect of their physical presentation. This is not a universal definition, rather it is a description of our use of the term in this paper.

${ }^{2}$ We use the term cis or cisgender when an individual's gender aligns with the one assigned to them at birth and matches what others expect of their physical presentation.

${ }^{3}$ We consider the term "desistance" to be flawed (see Theoretical Concerns section) but we use the term in this commentary because it is widely understood in the field of transgender health.
} 
transgender identity. This presumption links directly to questions about whether to support the self-identities of pre-pubescent gender nonconforming children. This paper reviews these studies and their interpretations by noting a number of positive contributions of this research before systematically exploring the limitations and overgeneralizations that render these studies less reliable than is often assumed.

In Table 1, we summarize the findings and compare several of the main measures and concepts explored in four key peer-reviewed publications between 2008 and 2013, frequently cited to support the $80 \%$ "desistance" estimation. These studies included gender non-conforming children who were referred for clinical care at early ages, and at follow-up in adolescence or early adulthood, categorized them as either "persisters" or "desisters."

\begin{tabular}{|c|c|c|c|c|c|}
\hline & Reference & $\begin{array}{l}\text { Drummond } \\
\text { et al. } \\
(\mathbf{2 0 0 8 )}\end{array}$ & $\begin{array}{l}\text { Wallien } \\
\text { et al. } \\
(2008)\end{array}$ & $\begin{array}{l}\text { Steensma } \\
\text { et al. } \\
(\mathbf{2 0 1 1})\end{array}$ & $\begin{array}{l}\text { Steensma } \\
\text { et al. } \\
(2013)\end{array}$ \\
\hline 1. & $\begin{array}{l}\text { N, number of subjects at } \\
\text { T0 }\end{array}$ & 37 (AFAB) & 77 & 53 & 127 \\
\hline 2. & T0-age & $3-12$ yrs & $5-12$ yrs & $<=12$ yrs & $<=12 \mathrm{yrs}$ \\
\hline 3. & $\begin{array}{l}\text { Selection by GIDC } \\
\text { criteria }\end{array}$ & $\begin{array}{c}\text { DSM-III } \\
\text { DSM-III-R } \\
\text { DSM-IV }\end{array}$ & $\begin{array}{c}\text { DSM-IV } \\
\text { DSM-IV-TR }\end{array}$ & $\begin{array}{c}\text { DSM-IV } \\
\text { DSM-IV-TR }\end{array}$ & $\begin{array}{c}\text { DSM-IV } \\
\text { DSM-IV-TR }\end{array}$ \\
\hline 4. & T0-GIDC / N & $60 \%$ & $75 \%$ & $100 \%$ & $63 \%$ \\
\hline 5. & $\begin{array}{l}\text { T0-GIDC- } \\
\text { subthreshold / N }\end{array}$ & $40 \%$ & $25 \%$ & $0 \%$ & $37 \%$ \\
\hline 6. & T1-age & $>=17 \mathrm{yrs}$ & $>=16 \mathrm{yrs}$ & $>=14 \mathrm{yrs}$ & $>=15 \mathrm{yrs}$ \\
\hline 7. & T1-desistant / N & $59 \%$ & $30 \%$ & $19 \%$ & $36 \%$ \\
\hline 8. & $\begin{array}{l}\text { T1-desistant-reported- } \\
\text { by-3rd-parties / N }\end{array}$ & $\mathrm{n} / \mathrm{a}$ & $13 \%$ & $\mathrm{n} / \mathrm{a}$ & $5 \%$ \\
\hline 9. & T1-persistent / N & $8 \%$ & $27 \%$ & $55 \%$ & $37 \%$ \\
\hline 10. & T1-non-binary & $\mathrm{n} / \mathrm{a}$ & $\mathrm{n} / \mathrm{a}$ & $2 \%$ & $\mathrm{n} / \mathrm{a}$ \\
\hline 11. & $\begin{array}{l}\text { T1-non- } \\
\text { participant / N }\end{array}$ & $32 \%$ & $30 \%$ & $25 \%$ & $22 \%$ \\
\hline 12. & $\begin{array}{l}\text { Reporting } \\
\text { of non-participants }\end{array}$ & $\begin{array}{l}\text { Deleted from } \\
\text { cohort }\end{array}$ & $\begin{array}{c}\text { Assumed to be } \\
\text { desistant }\end{array}$ & $\begin{array}{c}\text { Assumed to be } \\
\text { desistant }\end{array}$ & $\begin{array}{c}\text { Assumed to be } \\
\text { desistant }\end{array}$ \\
\hline 13 & $\begin{array}{l}\text { Reported } \\
\text { desistance rate }\end{array}$ & $88 \%$ & $73 \%$ & $45 \%$ & $63 \%$ \\
\hline
\end{tabular}

Table 1. Summary of relevant findings across four follow-up studies with gender non-conforming children (2008-2013) 
Notes on Table 1: All four studies selected subjects at T0 using the diagnostic criteria for Gender Identity Disorder of Childhood in the DSM-III through the DSM-IV, which did not explicitly require evidence of distress or of gender dysphoria (Row 3). In the Drummond et al. (2008) and Steensma et al. (2013) studies, nearly 40\% of subjects were "subthreshold" for GIDC diagnosis, and therefore did not meet those criteria (Row 4). In Row 9, rates are shown for persistent GIDC diagnosis or distress of gender dysphoria confirmed by re-assessment at $\mathrm{T} 1$ in adolescence or young adulthood. Far fewer subjects were confirmed with desisted GIDC diagnosis or with desisted gender dysphoria distress by re-assessment at T1 (Row 7), than were reported as desisters in these papers (Row 13). Five percent of Steensma et al. (2013) subjects were judged desistant based only on parental or other $3^{\text {rd }}$ party information at T1, with no reported examination of possible bias among those parties (Row 8). One subject in Steensma et al. (2011) identified as non-binary at T1 but was categorized as desistant (Row 10). Between $1 / 5$ th and $1 / 3$ rd of the samples did not participate in follow-up evaluation at T1 (Row 11). In Steensma (2013), 22\% of subjects were termed "nonresponders" at T1, including 19\% whose status was altogether unknown and 3\% who were reported as "indicated" desistant, though not confirmed by actual participation at T1 re-assessment (p. 584). Despite their outcome status being unknown or unconfirmed, they were categorized as desisters in all three Dutch studies

Wallien and Cohen-Kettenis (2008), Steensma et al. (2011) and Steensma et al. (2013) (Row 12). Desistance rates in the four papers were reported by the authors as follows: T1-desistant / T1participant for Drummond et al. (2008), where T1 non-participants were deleted from the cohort denominator; (T1-desistant + T1-non-participant) / N for Wallien and Cohen-Kettenis (2008); (T2-desistant + T2-non-binary + T2-non-participant) / N for Steensma et al. (2011); and (T2desistant + T2-desistant-reported-by-3rd-parties + T2-non-participant) / N for Steensma et al. (2013).

In the following commentary, we explore these studies in more depth by focusing on methodological, theoretical, ethical, and interpretive concerns, while noting the extrapolation that may have given rise to problematic treatment recommendations. First, some contributions from the original research are highlighted.

\section{Contributions of Follow-Up Studies with Gender Non-Conforming Children}

While this commentary offers critiques of desistance research and its clinical and popular interpretations, these studies have also made contributions to the literature worthy of recognition:

1. qualitative data on trans and gender diverse adolescents in clinical care, and

2. factors in anticipating medical transition for gender non-conforming children accessing clinical care

Steensma et al. (2011) offer some unique and valuable qualitative data to this body of literature. In the perspectives of the trans and gender diverse adolescents that are shared in this study, we are able to learn that for these youth, the ages of 10-13 were important for determining which direction their gender would take, and especially significant at this time were their feelings about their bodies and emerging sexualities. The qualitative nature of this research allows us to hear 
from two youth who had changed their minds about their gender after socially transitioning and who found the process of informing others very stressful. Although this difficulty is not the only possible outcome for youth who make more than one transition (see section on Interpretive Concerns), this research adds to our understanding of the pressures some young people may face when exploring gender in a transphobic society (Steensma et al., 2011).

A second contribution is that the four studies examined offer evidence that statements of transgender identity in childhood may help to anticipate transgender identity in adolescence or adulthood, and similarly, that the reported intensity of feelings of gender dysphoria in childhood may help to anticipate feelings of gender dysphoria in adulthood. Drummond et al. (2008) found that the two participants classified as gender dysphoric at follow-up "recalled significantly more cross-gender identity and role behavior in childhood than participants classified as having no gender dysphoria" (p. 41). Wallien \& Cohen-Kettenis (2008) reported that "all participants in the persistence group were given a complete GID diagnosis in childhood, whereas half of the group of desisting children was subthreshold for the diagnosis" (pp. 1420-1421). Finally, Steensma et al. (2013) reported that "explicitly asking children with GD with which sex they identify seems to be of great value in predicting a future outcome for [children diagnosed with gender dysphoria]." (p. 588). Both media and scientific discussion of this research have tended to downplay what is suggested here - the value of asking a child about their gender identity. Gender identity can indeed shift and evolve over time, and thus a young person who did not express trans identity in childhood should not be dismissed in their teen years on this basis, yet the persistence of this stated identity for some youth may be instructive. Regardless of predictive value, however, current approaches to care recommend that care providers prioritize young people's stated identities, perceptions and needs in the present moment, as opposed to attempting to estimate the likelihood of future identity and needs (Temple-Newhook et al., 2018; Hidalgo et al., 2013). As clinicians Schreier and Ehrensaft (2016) suggest: "Want to know a child's gender? Ask." We now turn to outlining a series of critiques and concerns regarding these studies, including: methodological concerns; theoretical concerns; ethical concerns; and interpretive concerns.

\section{Methodological Concerns}

We have identified the following methodological concerns in these four studies:

1. the potential misclassification of child research participants

2. the lack of acknowledgement of social context for research participants

3. the age of participants at follow-up, and

4. the potential misclassification of adolescent and young adult participants lost to followup.

The first two methodological concerns address the broad inclusion criteria for those studied in childhood. Rather than a representative group of transgender children, which is assumed in many interpretations, this literature focused on small groups of gender non-conforming children in two clinics. In Table 1, some, but not all of these children were diagnosed in childhood with Gender Identity Disorder in Children (GIDC), in prior editions of the Diagnostic and Statistical Manual of Mental Disorders (DSM) published by the American Psychiatric Association (1980, 1987, 1994, 2000). The GIDC category was replaced by Gender Dysphoria in Children (GDC) 
in the DSM-5 (American Psychiatric Association, 2013). Gender dysphoria was not defined as a diagnostic category until release of the DSM-5 in 2013, and therefore no subjects were formally diagnosed with gender dysphoria in childhood or at follow-up in any of these studies. However, the plain-language meaning of gender dysphoria, as distress regarding incongruent physical sex characteristics or ascribed social gender roles, has been established since the 1970s (Fisk, 1973). When these four studies refer to gender dysphoria, they are referring to this plain-language context of distress, and not the newer DSM-5 diagnostic category.

Due to such shifting diagnostic categories and inclusion criteria over time, these studies included children who, by current DSM-5 standards, would not likely have been categorized as transgender (i.e., they would not meet the criteria for gender dysphoria) and therefore it is not surprising that they would not identify as transgender at follow-up. Current criteria require identification with a gender other than what was assigned at birth, which was not a necessity in prior versions of the diagnosis. For example, in Drummond et al.'s (2008) study (Table 1) the sample consisted of many children diagnosed with GIDC, as defined in the DSM editions III, IIIR, and IV (American Psychiatric Association, 1980, 1987, 1994). Yet the early GIDC category included a broad range of gender non-conforming behaviours that children might display for a variety of reasons, and not necessarily because they identified as another gender. Evidence of the actual distress of gender dysphoria, defined as distress with physical sex characteristics or associated social gender roles (Fisk, 1973), was dropped as a requirement for GIDC diagnosis in the DSM-IV (American Psychiatric Association, 1994; Bradley et al., 1991). Moreover, it is often overlooked that $40 \%$ of the child participants did not even meet the then-current DSM-IV diagnostic criteria. The authors conceded: "...it is conceivable that the childhood criteria for GID may 'scoop in' girls who are at relatively low risk for adolescent/adult gender-dysphoria" and that " $40 \%$ of the girls were not judged to have met the complete DSM criteria for GID at the time of childhood assessment... it could be argued that if some of the girls were subthreshold for GID in childhood, then one might assume that they would not be at risk for GID in adolescence or adulthood" (p. 42). By not distinguishing between gender non-conforming and transgender subjects, there emerges a significant risk of inflation when reporting that a large proportion of "transgender" children had desisted. As noted by Ehrensaft (2016) and Winters (2014), those young people who did not show indications of identifying as transgender as children, would consequently not be expected to identify as transgender later, and hence in much public use of this data there has been a troubling over-estimation of desistance.

The second concern brings attention to the scope of the four studies discussed. Inferences from clinical research are always bound to specific locations and timeframes. Generalizing from research on gender identity is particularly problematic because notions of gender are highly dependent on social and historic context. For example, the meaning of gender conformity and non-conformity varies greatly, and in some non-Western and Indigenous cultures, gender diversity is either celebrated or considered non-problematic (Driskill, Finley, Gilley, \& Morgensen, 2011; Hunt, 2016). Furthermore, even within Toronto and the Netherlands, this research was limited to children whose parents chose to bring them to a clinic for diagnosis and treatment and thus may have believed the child's difference was a problem, and one that required psychological treatment. Children whose parents affirmed their gender (or who did not wish to or who were unable to access clinical treatment for any reason) were likely not included in these studies. This is significant because more recent work has shown that children raised by parents 
who validate their gender identity (Durwood, McLaughlin \& Olson, 2017; Olson \& Durwood, 2016) are likely to demonstrate a different (and in some respects healthier) life course than children with parents who are reluctant or unwilling to affirm gender non-conformity. The outcomes in the one group, therefore, may not generalize to the other.

The third methodological concern centres on the age at which follow-up was conducted. As noted in Table 1., only a minority of the young people who consented to be re-studied were diagnosed in adolescence with Gender Identity Disorder in Adolescents or Adults (GIDAA) and/ or chose to undergo certain trans-affirming surgeries in early adulthood. Yet in these four studies (Table 1), the mean age at follow-up ranged from 16.04 (Steensma, et al., 2013) to 23.2 years (Drummond, et al., 2008) and included adolescents as young as 14 years (Steensma et al., 2011). It is important to acknowledge that this represents a very early follow-up point in an individual's life, and that a trans person might assert or reassert their identity at any point in their life. An assumption has been made that young people not diagnosed with GID (or Gender Dysphoria in the current DSM-5) by late adolescence and/or not pursuing medical transition by a relatively early age, can then by default be "correctly" categorized as cisgender for their lifetime. However, this conclusion is contradicted when an unknown number of those counted as "desisters" may transition later, after the point of follow-up. Research has found that many transidentified individuals come out or transition later in adulthood (Reed et al., 2009).

A fourth methodological concern focuses on the misclassification of participants who did not participate in follow-up. A significant challenge to any longitudinal study is that a number of original participants will not be able to be located or will not provide research consent even if located, and so will be lost to follow-up (attrition). One can only continue to study those participants who can be located and contacted, and who also then consent to re-enrol. High levels of attrition limit the generalizability of longitudinal research findings, particularly when attrition might be non-random and related to the outcome. In the Drummond et al (2008) study, the data from participants who were lost to follow-up (32\% of participants) was removed from the study and analyses were conducted only with participants who returned. This list deletion method of handling attrition can be risky and can introduce bias, as Deng, Hillygus, Reiter, Si and Zheng (2013) note, because there is much scholarship suggesting that certain individuals are more likely to be lost to follow-up than others.

The three other studies analyzed in this review (Steensma et al., 2011; Steensma et al., 2013; Wallien \& Cohen-Kettenis, 2008) took what might be understood as an even riskier approach to handling attrition, by imputing all outcomes to missing participants as "desisters": in effect, venturing to guess about data that was unavailable. In these studies, 30\% of Wallien and CohenKettenis' (2008), 25\% of Steensma, et al.'s (2011), and 22\% of Steensma et al.'s (2013) participants who did not respond or did not participate at adolescent follow-up were counted as desisters (Table 1). In explanation, Steensma et al. (2011) write: "As the Amsterdam Gender Identity Clinic for children and adolescents is the only one in the country, we assumed that their gender dysphoric feelings had desisted, and that they no longer had a desire for sex reassignment." (p. 501). In other words, desistance was assessed based on whether or not participants re-engaged with this specific clinic by a specific time. This methodological choice neglects a number of important considerations: (1) the fact that not all transgender people wish to medically transition, yet still identify as trans; (2) the socio-economic or cultural factors that may influence whether an adolescent seeks psychological or medical treatment; (3) the possibility of a 
negative perception of the initial clinic experience, which might discourage a youth's return; (4) the possibility of a youth moving out of the country, being institutionalized in a mental health facility or even the possibility of death (including suicide), none of which negate a trans identity; and, (5) the possibility that some young people might repress their gender identity for a period of time, due to societal transphobia, family rejection, safety, employment and housing security, or pressure from therapies designed to discourage trans identity (Kennedy \& Hellen, 2010). The phenomenon of realizing one's gender identity long before expressing it to others has been illustrated in the Trans PULSE study conducted in Ontario, Canada. While 59\% of participants had socially transitioned within the four years prior to study, the majority of participants first realized that they were trans before the age of 10 years (Scheim \& Bauer, 2015). The classification (and potential misclassification) of participants lost to follow-up as desisters, could result in a significant overestimation of the number of young adults assumed to be cisgender.

\section{Theoretical Concerns}

We have identified the following theoretical concerns in the four studies:

1. assumptions inherent in "desistance" terminology

2. binary gender framework, and

3. presumption of gender stability as a positive outcome

The first theoretical concern pertains to the unnecessary conceptualizing of shifts in gender identity as either "persistence" or "desistance." The etymology of the word desistance (from the Latin desistere, meaning to stop or cease) reveals that the dominant framework for understanding variations of childhood gender is rooted in the field of criminology (e.g. Farrall et al., 2010; Sampson \& Laub, 2003; Stouthamer-Loeber et al., 2004), where desistance is defined as "the cessation of offending or other antisocial behavior" (Kazemian, 2009). This choice of terminology positions gender identity development as a pathway of either 'normal' or 'deviant' identity. In addition, the use of the term desistance in all four studies positions cisgender and transgender as immutable discrete categories (Serano, 2016). In this framework, cisgender identity tends to be seen as the healthy opposite of a problematic transgender identity. Assertion of a cisgender identity at any point in the life cycle is often assumed to be valid and invalidates any previous assertion of transgender identity; yet a transgender identity is only viewed as valid if it is static and unwavering throughout the life course and if it emerges in a particular time period (the period of study). In our research and practice experience, a rigid categorization of gender does not reflect the lived experiences of transgender and gender non-conforming children. A child who has identified as transgender may indeed at some point in their life assert their birth-assigned gender, but this is not necessarily the end of their gender journey.

A second theoretical concern is that the terminology of "desistance" depends on a binary understanding of gender. Each of the four studies used binary language to refer to children as "boys and girls," prioritizing the sex they were assigned at birth, as opposed to their own identity. Furthermore, this language makes non-binary and intersex identities invisible. For example, Steensma et al. (2011) define the following individual as a desister and thus cisgender, in spite of the young person's own self-identification: "At the time of the interview, Desister 1 (18 years of age), still desired to be a woman, with breasts and the possibility of giving birth. 
However, he considered himself 50\% male and 50\% female" (p. 512). The authors acknowledge that not every person who experiences gender dysphoria will seek medical transition or assert a binary gender identity. They add that "[i]t would be worthwhile to follow [this non-binaryidentifying young person's] development much longer, to see whether [their] ambiguous gender feelings were just part of a passing phase (either into desistence or persistence) or whether they remained a stable characteristic of this person" (p. 513). We question here the characterization of a self-described " $50 \%$ male and 50\% female" research participant as "ambiguous," instead of a term supplied by the participant, and hope that if this study were conducted today, there would be greater recognition of non-binary gender identities.

A third theoretical concern is the embedded assumption in these studies that "stability" of gender identity is a positive health outcome that should be prioritized for all children. A desistance framework reinforces a static understanding of gender that hinders us from understanding the experience of a child whose gender identity is more fluid, or changable over time. While the current understanding of the developmental trajectories of gender state that most children are aware of their gender identity by the age of 4 years (American Association of Pediatrics, Human Rights Commission, \& American College of Osteopathic Pediatricians, 2016), this does not suggest that those children for whom gender identity is more fluid or slower to develop, are not also following a healthy developmental trajectory. While many individuals experience their gender identity as stable throughout their lifetimes, others find that a gender that "fits" at age four may be different from what fits at age seven, age 18, or age 65. None of these identities are "wrong"; instead they may have been perfectly and precisely the right fit for that person at that moment. Further, for some individuals the most consistent aspect of their gender is that it is fluid or ever-changing. Many individuals move through a process of exploration and/or "[renegotiation] of one's gender throughout childhood or adulthood with no observable detriment to their mental health" (Ehrensaft, 2016, p. 59). An alternative framework would conceptualize changes and developments in gender identity not as errors in the development of a 'true' gender, but as necessary paths of exploration along a journey of self-discovery that might be lifelong. Finally, as Bryant (cited in Schwartzapfel, 2013) points out, it is likely that the future identities of today's children cannot be known for certain, given that the language to describe or acknowledge these identities may not yet exist. There is no evidence that caring for a child in the present requires knowing their future adult gender identity. A longitudinal research design that records identity at two relatively early intervals, is therefore arguably not the most appropriate tool for understanding either children's or adult's health needs.

The dominance of binary language in interpretations of desistance research is implied in statements such as "the majority of those who desist by or during adolescence grow up to be gay, not transgender" (Drescher \& Pula, 2014, p. S18). Such statements conflate gender identity and sexual orientation, with an underlying assumption that the options are between identifying as gay and cisgender, or as transgender. Framing research on childhood gender diversity in terms of desistance and persistence tends to reproduce and reinforce this limited binary perspective on gender and sexuality. The conception of gender reflected in these studies represents a historical and cultural moment that differs from both traditional and current understandings of gender and sexuality. As scholars of human sciences, we are reminded that clinical and research disciplines are human-made frameworks to understand complex identities and actions. In scientific and medical research, it is important to acknowledge that the categories used to study people (e.g., 
desisters) often reflect the assumptions and beliefs of the researchers themselves. We suggest that if we find that people do not fit our categories, then it is the categories that must change.

\section{Ethical Concerns}

We have also identified ethical concerns in these four studies:

1. intensive treatment and testing of child participants,

2. questionable goals of treatment, and

3. lack of consideration of children's autonomy

From an ethical perspective, it is important to consider that research itself is an intervention. These studies took place in the context of gender clinics in which children were put through a substantial degree of testing over periods of months or years. For example, Drummond et al. (2008) report that in their study, children and their parents were administered: the Draw a Person test; a free-play task; the Playmate and Playstyle Preferences Structured Interview; sex-typed responses on the Rorschach test; the Gender Identity Questionnaire for Children; a measure of activity level/extraversion; and the Games Inventory. Critiques of the practice of diagnosing gender non-conforming children (with the GIDC diagnosis from DSM-III, DSM III-R, DSM IV) began to be published in the late 1990s and argued that healthy children might have their selfesteem damaged and their trust in therapy eroded by being brought into stigmatizing diagnostic and treatment settings (Isay, 1997; Langer \& Martin, 2004; Menvielle, 1998; Pickstone-Taylor, 2003; Vanderburgh, 2009). This concern continues and highlights the need for research into possible adverse effects and ethical complications related to extensive and ongoing psychological testing for children in clinical settings.

A second ethical concern is that many of the children in the Toronto studies (Drummond et al., 2008; Zucker \& Bradley, 1995) were enrolled in a treatment program that sought to "lower the odds" that they would grow up to be transgender (Drescher \& Pula, 2014; Zucker, Wood, Singh \& Bradley, 2012; Paterson, 2015). Zucker et al. (2012) wrote: “...in our clinic, treatment is recommended to reduce the likelihood of GID persistence" (p. 393). In a Hastings Centre Report on LGBT Bioethics, Drescher and Pula (2014) explain the Toronto clinic's approach: "The clinic claims its approach decreases the likelihood that GD will persist into adolescence, leading to adult transsexualism, which, for various reasons, such as social stigma and a lifetime of medical treatment, is an outcome the clinic considers undesirable" (pp. S17-18). Drescher and Pula (2014) make an ethical inquiry about this approach: "Since no clinician can accurately predict the future gender identity of any particular child, shouldn't we assume that efforts to discourage cross-gender play and identifications may be experienced as hurtful and possibly even traumatic, since, for some children, gender dysphoria will persist into adolescence and adulthood?" (p. S19). Drescher and Pula elaborate: "Are the harms so unknown or so great that it is unethical to offer such treatment at all?" (p. S19). The Toronto clinic was closed in 2015 (Schreier \& Ehrensaft, 2016), but questions regarding the interpretation of research conducted in this setting are ongoing.

Drummond et al. (2008) report that their Dutch follow-up study provides information on the "natural histories" of "girls with gender identity disorder" (p. 34), yet the clinical pursuit of an a priori goal for a child's gender is already inconsistent with the meaning of the term "natural 
history", which refers to the natural progression of a condition in the absence of treatment (Center for Disease Contol, 2012). While the Netherlands clinic did not discourage children from exploring their gender expression, it did discourage children from socially transitioning prior to puberty (Drescher \& Pula, 2014; Steensma et al., 2013). It is important to acknowledge that discouraging social transition is itself an intervention with the potential to impact research findings, as discussed below in reference to interpretive concerns.

A lack of consideration of children's autonomy in desistance literature is a third ethical concern. Children have their own rights to autonomy and self-determination (Powell, 2012). ${ }^{4}$ However, children's own assertions of identity and their own perspectives on their gender are subordinate in this literature to the diagnostic measures created by clinicians and researchers. In one case, Steensma et al. (2013) write that, "because the role of parental report on gender-variant behaviors and surface behaviors such as gender role transitioning are of less value in predicting a future persistence of gender dysphoria in [children assigned female at birth], it seems important to provide extra focus on [assigned-female children's] own experiences of cross-gender identification and wishes" (p. 588). We agree with this statement of concern for children's own identification and wishes and would extend it to children of all genders.

This consideration of children's own wishes should also extend to their right to decline participation in research. In the four studies, there is an absence of information about whether research participation was optional and if steps were taken to ensure that children could decline research consent while continuing to receive needed services. The need to decouple research participation from access to medical and mental health care is consistent with emerging proposals for ethical research with transgender subjects (Adams et al., 2017; Devor, Bauer, Pyne, Heinz \& Marshall, 2016)

These ethical concerns raise questions about the validity of research with children whose parents believe they have a medical problem, who are subjected to a high level of testing and treatment, who are disallowed or discouraged from asserting their own gender identity, and who are being raised in a broader society that often punishes perceived transgressions of male and female boundaries. Interpretations of desistance research have assumed that the difference recorded between measures of gender dysphoria and/or identity at childhood and at early adulthood mean that "the majority of [trans children] will become comfortable with their natal gender over time" (Byne et al., 2012, p. 4). However, the larger social context shaping young people's identities is essential to consider. Wallien and Cohen-Kettenis (2008) point out that there are challenges in research based on self-report of sexual orientation, given that "social desirability is a key validity issue in the assessment of sexual orientation during the adolescent years" (p. 1421). It would be fair to assume that the same concern would hold for self-report of gender identity. Drummond et al. (2008) attempt to account for the possible effect of social desirability by assessing participant responses to questions about a range of socially undesirable issues, yet it is unclear if this can account for the way transgender identity might be uniquely undesirable in a clinic that explicitly seeks to discourage it (see Zucker et al., 2012). In interpreting the results of these studies, it is important to ask questions about limitations in the validity of self-report when the research is conducted under conditions that might compromise authentic responses, for example, within a clinic where transgender identity is defined as less desirable than cisgender identity.

\footnotetext{
${ }^{4}$ The authors acknowledge that beliefs about children's autonomy vary cross-culturally.
} 


\section{Interpretive concerns}

We also have concerns with the authors' interpretation in these four studies, including:

1. the assumption that unknown future adult needs should supersede known childhood needs, and

2. the underestimation of harm when attempting to delay or defer transition

Desistance studies are often drawn on to suggest that delaying a young person's social transition is justified because it may prevent them from having to transition back in the future. There is an assumption that a second transition would be distressing. Steensma et al. (2013) write: "the percentage of transitioned children is increasing ... which could result in a larger proportion of children who have to change back to their original gender role, because of desisting GD, accompanied with a possible struggle" (pp. 588-589). Yet we note that this projected struggle is acknowledged only as "possible" rather than certain (p. 589). Similarly, in a letter to the editor entitled "Gender Transitioning before Puberty?", Steensma and Cohen-Kettenis (2011) write: "It is conceivable that the drawbacks of having to wait until early adolescence (but with support in coping with the gender variance until that phase) may be less serious than having to make a social transition twice" (p.649). Yet again, this statement itself acknowledges that future distress is merely "conceivable" and again, not certain. As Ehrensaft, Giammattei, Storck, Tishelman and Keo-Meier (2018) note, the evidence that a second transition would be traumatic is very thin, drawn from a case study of two children who found a reversion back to their original gender challenging in Steensma and Cohen-Kettenis's (2011) clinic. Yet in another clinic, (EdwardsLeeper \& Spack, 2012), a de-transitioning girl and her mother expressed gratitude for her opportunity to live as a boy for a time, and they felt that if she had been forced to live as a girl for her entire childhood, that her mental health would have suffered. Thus, with many possible outcomes for the future, young people's needs in the present must be prioritized.

A further related interpretive concern is the presumption that childhood needs, adolescent needs, and adult needs should "match" in a simplistic sense. Yet a child may need to use 'she' pronouns in childhood, 'he' pronouns in adolescence, and 'they' pronouns in adulthood. Nothing about this is inherently problematic. What is needed in childhood may differ from what is needed in adolescence or adulthood, but this does not negate childhood needs. What is problematic is the assumption that a potential future shift in a child's gender identity is a justification for suppressing or redirecting their assertion of identity in childhood.

The underestimation of harm in suppressing or redirecting children's gender expression, is the most serious concern in interpretations of desistance literature. That gender identity or expression may change among children (or adults) does not support the hypothesis that it is preferable or possible to externally "coax" gender in a particular direction, or that this could be done without harm. In contrast, the positioning of this goal as benign ignores the potential harms to young people who have undergone such treatments (Bryant, 2006). A 2013 attachment-based theoretical comparison of gender therapies for children concluded that there is a risk that children who are discouraged from expressing their gender identity may integrate shame into their fundamental sense of self (Wallace \& Russell, 2013). Drescher and Pula (2014) offer: "It could be construed ... that clinical attempts to prevent transsexualism, no matter how well meaning, 
are unethical because they demean the dignity of gender-variant children" (p.S19). Although the term "conversion therapy" originally referred to religious-based therapies purported to change an individual's sexual orientation, as noted by the American Academy of Child and Adolescent Psychiatry (AACAP), the meaning of the term has expanded in recent years to encompass efforts to change an individual's core gender identity or promote a preferred outcome for their gender identity, therapies that according to the AACAP "lack scientific credibility" (AACAP, 2018). In our experience, disallowing children's assertions of gender identity is far from a "neutral" option. From a developmental perspective, a child who is repeatedly discouraged when she earnestly insists on being called "she," is learning, on a fundamental level, that (1) she cannot trust her own knowledge of herself and, (2) the adults she depends on may not value her for who she knows herself to be.

Lastly, while many clinicians would not propose attempting to alter gender expression, many still interpret desistance research as support for delaying transition, lest a trans identity becomes more likely. Steensma et al. (2013) write: “...with a link between social transitioning and the cognitive representation of the self [social transition may] influence the future rates of persistence" (pp. 588-9). Yet we would ask why an increase in the number of transgender people ("persistence") would be interpreted in a negative light, and how this sentiment could be consistent with the WPATH position that transgender identity is a matter of diversity not pathology (Coleman et al., 2012). Drescher and Pula (2014) as well as Ehrensaft et al. (2018) note that at times there appears to be a willingness to expose transgender children to the stress of living in a gender they do not identify with, in order to protect cisgender children from the possibility of "mistakenly" transitioning. Yet we would contend that the quality of life of transgender children is no less important and no less valuable than that of cisgender children.

\section{Discussion: What is the future of care for trans and gender diverse children?}

It is essential to distinguish between the evidence provided by these studies and the flawed interpretations of these studies that may be used to shape care for trans and gender nonconforming children. These concerns address the differences between the questions: (1) how should children's gender identities develop over time? and, (2) how should children best be supported as their gender identity develops?

In the first question, desistance studies give us some information about how some gender nonconforming children's identities have been recorded in certain cultural and clinical circumstances. However, the World Professional Association for Transgender Health Standards of Care now recognizes gender non-conformity as a matter of diversity not pathology (Coleman et al., 2012, pp. 1, 3, 4, 6): thus no path need be considered the correct or healthy trajectory. While transgender identity has certainly been pathologized in Western medicine, present-day best practice promotes the recognition of a plurality of healthy developmental trajectories for gender.

In the second question, the affirmative care model, which is now practiced by the majority of North American gender clinics (Ehrensaft, 2016), promotes support for children as their gender identity develops, with no expectations for any particular direction of the gender journey. In the affirmative care model, children are provided with the space to explore and try out different self- 
expressions to discover a place that is comfortable for them (Ehrensaft, 2016; Hidalgo et al., 2013). This means that instead of attempting to direct a child toward a particular identity, parents and caregivers accept a child's own individual journey. Within this model of care, adult scrutiny and investment in any particular current or future gender identity are removed. Children are not prevented from exploring aspects of gender as they develop a sense of what fits for them through the language available to them at that time. Within this model of care, it is understood that the gender that is the 'right fit' may differ at different ages and stages of life. Emergent research on the health and well-being of trans children who are affirmed in their gender identity, indicates mental health outcomes equivalent with cisgender peers (Olson et al., 2016; Durwood et al., 2017). As Sherer (2016) and Turban (2017) note, this is in stark contrast to the high levels of psychological distress and behavioural problems documented among children who were discouraged from asserting their identities in childhood (Cohen-Kettenis et al., 2003).

From a research perspective, noting the gap between the questions of (1) gender trajectories and (2) the health of gender non-conforming children, we suggest that longitudinal studies about identity "desistance" or "persistence" are not the best tools for understanding the needs of gender non-conforming children. As work begins on the $8^{\text {th }}$ version of the Standards of Care by the World Professional Association for Transgender Health, we call for a refocus of research and clinical practice with transgender and gender non-conforming children and youth, to prioritize listening to how young people articulate their wishes and needs. The potential harm inherent in approaches that lack support for children's own assertions must be acknowledged as we create a more nuanced framework for understanding and caring for gender non-conforming children. Such a framework would integrate an understanding of intersectionality (Cole, 2009; Crenshaw, 1991; Collins, 1990; Singh, 2013), which involves taking into account the multiple systems of oppression that simultaneously shape trans and gender non-conforming children's lives.

\section{Conclusion}

In this critical review of four primary follow-up studies with gender non-conforming children in Toronto, Canada and the Netherlands (Table. 1), we identify a total of twelve methodological, theoretical, ethical, and interpretive concerns as well as two often-overlooked contributions of this literature. We conclude that, while our understanding of gender diversity in adults has progressed, the tethering of childhood gender identity to the idea of "desistance" has stifled similar advancements in our understanding of children's gender diversity. As we progress towards a fuller understanding of children's gender in all its complexity, it will be important to move beyond longitudinal studies of identity that seek to predict children's futures, and instead prioritize respect for children's autonomy in the present. For all the resources devoted to studying these children, we have much more to learn by listening to them.

Conflict of Interest: The authors declare that they have no conflict of interest.

Acknowledgements: The authors would like to thank Ayden Scheim and Greta Bauer as well as the anonymous reviewers and editors of this special issue for their helpful comments on earlier drafts. 


\section{References}

Adams, N., Pearce, R., Veale, J., Radix, A., Castro, D., Sarkar, A., \& Thom, K.C. (2017). Guidance and ethical considerations for undertaking transgender health research and institutional review boards adjudicating this research. Transgender Health, 165-174.

American Academy of Child \& Adolescent Psychiatry. (2018, February). Conversion Therapy. Retrieved from: https://www.aacap.org/AACAP/Policy_Statements/2018/Conversion_ Therapy.aspx

American Association of Pediatrics, Human Rights Commission, \& American College of Osteopathic Pediatricians. (2016). Supporting and caring for transgender children. Washington, DC: Human Rights Commission. Retrieved from:

http://www.hrc.org/resources/supporting-caring-for-transgender-children.

American Psychiatric Association. (1980). Diagnostic and Statistical Manual of Mental Disorders (3rd ed.). Washington, DC: Author.

American Psychiatric Association. (1987). Diagnostic and Statistical Manual of Mental Disorders (3rd ed. rev). Washington, DC: Author.

American Psychiatric Association. (1994). Diagnostic and Statistical Manual of Mental Disorders (4th ed.). Washington, DC: Author.

American Psychiatric Association. (2000). Diagnostic and Statistical Manual of Mental Disorders (4th ed. rev.). Washington, DC: Author.

American Psychiatric Association. (2013). Diagnostic and Statistical Manual of Mental Disorders (5th ed. rev.). Washington, DC: Author.

Bradley, S., Blanchard, R., Coates, S., Green, R., Levine, S., Meyer-Bahlburg, H., Pauly, I., \& Zucker, K. (1991). Interim report of the DSM-IV subcommittee on gender identity disorders, Archives of Sexual Behavior,20, 333-343.

Bryant, K. (2006). Making gender identity disorder of childhood: Historical lessons for contemporary debates. Sexuality Research and Social Policy, 3, 23-39. https://doi.org/10.1525/srsp.2006.3.3.23

Byne, W., Bradley, S., Coleman, E., Eyler, A.E., Green, R., Menvielle, E.J., Meyer-Bahlburg, H.F.L., Pleak, R.R., \& Tompkins, D.A. (2012). Report of the American Psychiatric 
Association Task Force on Treatment of Gender Identity Disorder. Archives of Sexual Behavior, 41, 759-796.

Center for Disease Control. (2012). Principles of Epidemiology in Public Health Practice. Retrieved from: https://www.cdc.gov/ophss/csels/dsepd/ss1978/lesson1/section9.html

Cohen-Kettenis, P. T., Owen, A., Kaijser, V. G., Bradley, S. J., \& Zucker, K. J. (2003).

Demographic characteristics, social competence, and behavior problems in children with gender identity disorder: a cross-national, cross-clinic comparative analysis. Journal of Abnormal Child Psychology, 31, 41-53

Cole, E. (2009). Intersectionality and research in psychology. American Psychologist, 64, 170180.

Coleman, E., Bockting, W., Botzer, M., Cohen-Kettenis, P., DeCuypere, G., Feldman, J., ... Zucker, K. (2012). Standards of care for the health of transsexual, transgender, and $\quad$ gender- nonconforming people (Ver. 7). International Journal of

Transgenderism, 13(4), $\quad$ 165-232. doi:10.1080/15532739.2011.700873

Collins, P. (1990). Black feminist thought: Knowledge, consciousness, and the politics of empowerment. Boston: Unwin Hyman.

Crenshaw, K. (1991). Mapping the margins: Intersectionality, identity politics, and violence against women of color. Stanford Law Review, 43, 1241-1299.

Deng, Y., Hillygus, D., Reiter, J., Si, Y. \& Zheng, S. (2013). Handling attrition in longitudinal studies: The case for refreshment samples. Statistical Science, 28, 238-256.

Devor, A., Bauer, G., Pyne, J., Heinz, M. \& Marshall, Z. (2016, June). Generating National Guidelines for Research Involving Transgender People. Paper presented at the World Professional Association for Transgender Health Biennial Symposium, Amsterdam, ND.

Driskell, Q., Finley, C., Gilley, B. J., \& Morgensen, S. L. (2011). Queer indigenous studies: Critical interventions in theory, politics and literature. Tuscon, AR: University of Arizona Press.

Drescher, J. \& Pula, J. (2014). Ethical issues raised by the treatment of gender-variant prepubescent children. LGBT Bioethics: Visibility, Disparities, and Dialogue, special report, Hastings Center Report,44, S17-S22. DOI: 10.1002/hast.365

Drescher, J. (2013). Controversies in gender diagnoses. LGBT Health, 1, 10-14.

Drummond, K., Bradley, S., Peterson-Badali, M., \& Zucker, K. (2008). A follow-up study of girls with gender identity disorder. Developmental Psychology, 44, 34-45. 
Durwood, L., McLaughlin, K., \& Olson, K. (2017). Mental health and self-worth in socially transitioned transgender children. Journal of the American Academy of Child and Adolescent Psychiatry, 56(2), 116-123.

Edwards-Leeper, L., \& Spack, N. P. (2012). Psychological evaluation and medical treatment of transgender youth in an interdisciplinary "Gender Management Service" (GeMS) in a major pediatric center. Journal of Homosexuality, 59, 321-336.

Ehrensaft D. (2016). The gender creative child. New York, NY: The Experiment Publishing.

Ehrensaft, D., Giammattei, S., Storck, K., Tishelman A. and Keo-Meier, C. (2018): Prepubertal social gender transitions: What we know; what we can learn-A view from a

gender affirmative lens, International Journal of Transgenderism, DOI: 10.1080/15532739.2017.1414649

Farrall, S., Bottoms, A., \& Shapland, J. (2010). Social structures and desistance from crime. European Journal of Criminology, 7, 546-70.

Fisk, N. (1973). Gender dysphoria syndrome. (The how, what, and why of a disease). In D. Laub \& P. Gandy (Eds.), Proceedings of the second interdisciplinary symposium on gender dysphoria syndrome (pp. 7-14). Palo Alto, CA: Stanford University Press.

Green, R. (1987). The "sissy boy syndrome" and the development of homosexuality. New Haven, CT: Yale University Press.

Hidalgo, M., Ehrensaft, D., Tishelman, A., Clark, L., Garofalo, R., Rosenthal, S., Spack, N., \& Olson, J. (2013). The gender affirmative model: What we know and what we aim to learn. Human Development, 56, 285-290.

Hunt, S. (2016). An introduction to the health of Two-Spirit people: Historical, contemporary and emergent issues. Prince George, BC: National Collaborating Centre for Aboriginal Health. Retrieved from: https://www.ccnsa-nccah.ca/docs/emerging/RPT-HealthTwoSpiritHunt-EN.pdf

Isay, R. (1997). Remove Gender Identity Disorder from DSM. Psychiatric News. http://psychnews.org/pnews/97-11-21/isay.html

Kazemian, L. (2009). Desistance. Oxford Bibliographies. Retrieved from: http://www.oxfordbibliographies.com/view/document/obo-9780195396607/obo9780195396607-0056.xml

Langer, S. J, \& Martin, J. I (2004). How dresses can make you mentally ill: Examining gender identity disorder in children. Child and Adolescent Social Work Journal, 21, 5 23.

Menvielle, E. (1998) Gender Identity Disorder. Journal of the American Academy of 
Child and Adolescent Psychiatry, 37(3), 243-44.

Money, J., \& Russo, A.J. (1979). Homosexual outcome of discordant gender identity/role:

Longitudinal follow-up. Journal of Pediatric Psychology, 4, 29-41.

Olson, K.R. (2016). Prepubescent transgender children: What we do and do not know. Journal of the American Academy of Child and Adolescent Psychiatry,55, 155-56.

Olson, K. \& Durwood, L. (2016, January 14). Are parents rushing to turn their boys into girls? Slate. Retrieved from:

http://www.slate.com/blogs/outward/2016/01/14/

what_alarmist_articles_about_transgender_children_get_wrong.html

Olson, K., Durwood, L., DeMeules, M., \& McLaughlin, K. (2016). Mental health of transgender children who are supported in their identities. Pediatrics, 137(3), 1-8.

Pickstone-Taylor, S. (2003). Children with gender nonconformity. Journal of the American Academy of Child and Adolescent Psychiatry, 42, 266.

Powell, M.A., Fitzgerald, R., Taylor, N.J., \& Graham, A. (2012). International literature review: Ethical issues in undertaking research with children and young people. Literature review for the Childwatch International Research Network. Lismore: Southern Cross University, Centre for Children and Young People / Dunedin: University of Otago, Centre for Research on Children and Families. Retrieved from http://childethics.com/wp-content/uploads/2013/09/Powell-et-al-2012.pdf

Pyne, J. (2012). Supporting gender independent children: A Rainbow Health Ontario fact sheet. Toronto: Rainbow Health Ontario. Retrieved from: https://www.rainbowhealthontario.ca/wp-content/uploads/woocommerce uploads/2012/1 0/RHO FactSheet GIC E1.pdf

Pyne, J. (2014). Health and wellbeing among gender independent children: A critical review of the literature. In E. Meyer \& A. Pullen Sansfacon (Eds.) Supporting transgender and gender creative youth: Schools, families, and communities in action (pp. 26-40). Peter Lang: New York.

Reed, B., Rhodes, S., Schofield, P., \& Wylie, K. (2009). Gender variance in the UK. Prevalence, incidence, growth and geographic distribution. London, UK: GIRES - the Gender Identity Research and Education Society. Retrieved from: http://www.gires.org.uk/assets/ Medpro-Assets/GenderVarianceUK-report.pdf

Sampson, R., \& Laub, J. (2003). Desistance from crime over the life course. J. Mortimer \& M. Shanahan (Eds.), Handbook of the life course, pp. 295-309. New York: Springer.

Scheim, A.I., \& Bauer, G.R. (2015). Sex and gender diversity among transgender persons in 
Ontario, Canada: Results from a respondent-driven sampling survey. The Journal of Sex Research, 52(1), 1-14. https://doi.org/10.1080/00224499.2014.893553

Schreier, H. \& Ehrensaft, D. (2016). Want to know a child's gender? Ask. San Francisco Gate. Retrieved from: http://www.sfgate.com/opinion/article/Want-to-know-a-child-s-gender-Ask-6843665.php

Serano, J. (2016). Desistance, detransition and disinformation: A guide for understanding transgender children debates. Medium. Retrieved from: https://medium.com/@juliaserano/detransition-desistance-and-disinformation-a-guidefor-understanding-transgender-children-993b7342946e

Sherer, I. (2016). Social transition: Supporting our youngest transgender children. Pediatrics, 137(3), e20154358.

Singh, A. (2013). Transgender youth of color and resilience: Negotiating oppression and finding support. Sex Roles, 68, 690-702.

Speigel, A. (2008). Two families grapple with sons' gender preferences. National Public Radio, Retrieved from http://www.npr.org/templates/story/story.php?storyId=90247842

Spitzer, R., Gibbon, M., \& First, M. (eds.) (2004). Treatment companion to the DSM-IV-TR casebook. Washington, DC: American Psychiatric Publishing

Steensma, T., Biemond, R., de Boer, F. \& Cohen-Kettenis, P. (2011). Desisting and persisting gender dysphoria after childhood: A qualitative follow-up study. Clinical Child Psychology \& Psychiatry, 16(4), 499-516

Steensma, T. \& Cohen-Kettenis, P. (2011). Gender transition before puberty? Archives of Sexual Behaviour, 40, 649-650.

Steensma, T., McGuire, J., Kreukels, B., Beekman, A., \& Cohen-Kettenis, P. (2013). Factors Associated With desistance and persistence of childhood gender dysphoria: A quantitative follow-up study. Journal of the American Academy of Child \& Adolescent Psychiatry,52(6), 582-590.

Stouthamer-Loeber, M., Wei, E., Lober, R., \& Masten, A. (2004). Desistance from persistent serious delinquency in the transition to adulthood. Development \& Psychopathology, 16(4), 897-918.

Temple-Newhook, J., Winters, K., Pyne, J., Jamieson, A., Holmes, C., Feder, S., Picket, S. \& Sinnott, M. (in press 2018). Teach Your Parents (and Providers) Well: A Call for ReFocus on the Health of Trans and Gender-Diverse Children. Canadian Family Physician.

Travers, R., Bauer, G., Pyne, J., Bradley, K., Gale, L. \& Papadimitriou, M. (2012). Impacts of strong parental support for trans youth: A report prepared for Children's Aid Society of 
Toronto and Delisle Youth Services. Retrieved from http://transpulseproject.ca/research/impacts-of-strong-parental-support-for-trans-youth/

Turban, J. (2017). Transgender Youth: The Building Evidence Base for Early Social Transition. Journal of the American Academy of Child \& Adolescent Psychiatry,56(2), 101-102.

Vanderburgh, R. (2009). Appropriate therapeutic care for families with pre-pubescent transgender/gender-dissonant children. Child Adolescent Social Work Journal, 26, 135154.

Wallace R., \& Russell, H. (2013). Attachment and shame in gender nonconforming children and their families: Toward a theoretical framework for evaluating clinical interventions. International Journal of Transgenderism, 14(3), 113-126.

Wallien, M., \& Cohen-Kettenis, P. (2008). Psychosexual outcome of gender-dysphoric children. Journal of American Academy of Child \& Adolescent Psychiatry,47, 1413-1423.

Winters, K. (2014, February). Methodological questions in childhood gender identity 'desistance' research". Paper presented at the World Professional Association for Transgender Health Biennial Symposium, Bangkok, Thailand. doi: https://gidreform.wordpress.com/2017/02/10/revisiting-flawed-research-behind-the-80childhood-gender-dysphoria-desistance-myth/

Zucker, K. \& Bradley, S. (1995). Gender identity disorder and psychosexual problems in children and adolescents. New York: Guilford Press.

Zucker, K. (1999). Commentary on Richardson's (1996) 'Setting limits on gender health.' Harvard Review of Psychiatry, 7, 37-42.

Zucker, K.J., Wood. H., Singh, D. \& Bradley, S. (2012). A developmental, biopsychosocial model for the treatment of children with Gender Identity Disorder. Journal of Homosexuality, 59, 369-397.

Zuger, B. (1984). Early effeminate behavior in boys: Outcome and significance for homosexuality. Journal of Nervous and Mental Disease, 172, 90-97. 